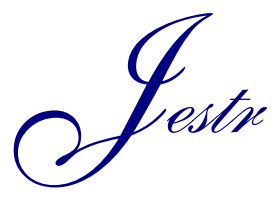

Journal of Engineering Science and Technology Review 11 (3) (2018) 61 - 69

Research Article

www.jestr.org

\title{
Active Return Control Strategy of Electric Power Steering System Based on Disturbance Observer
}

\author{
Zhipeng Li, Songzhuo Shi* and Chao Zhang
}

School of Traffic, Northeast Forestry University, Harbin 150040, China

Received 9 February 2018; Accepted 17 June 2018

\begin{abstract}
As the market for motor steering components and parts becomes increasingly mature, the requirement for vehicle steering stability becomes strict. Steering wheel torque may fluctuate when the vehicle is running on an uneven road and under steering reversal condition. A change in the return torque of the steering wheel may result in insufficient return or return overshoot, which can affect the vehicle's steering stability. To overcome the adverse effect of random pavement excitation on vehicle return-ability, an electric power steering (EPS) system return control algorithm that integrates disturbance observer and back-stepping sliding-mode algorithm was proposed in this study. First, a return control strategy based on the return torque needed by the vehicle was established. Under the return condition, the observed value of disturbance observer was considered the theoretical basis. Then, the power-assisting motor return current of the EPS system was compensated, and the target current value of return control was determined. A full-vehicle model was established in Adams dynamic simulation software, and a controller model of the EPS system was built in MATLAB software. A random pavement excitation signal was then added in the Adams full-vehicle model, and return-ability was evaluated using vehicle yaw velocity and lateral acceleration. Finally, the stability of the designed system was verified on the test bed. Results show that the return torque provided by the power-assisting motor is verified through a comprehensive performance bench of $2 \mathrm{~N} . \mathrm{m}$, and the maximum return residual angle of the steering wheel is kept within $5^{\circ}$, thereby improving the vehicle steering stability. This study provides a theoretical reference for the return response of EPS systems under external excitations of different frequencies.
\end{abstract}

Keywords: Electric Power Steering System, Disturbance State Observer, Return Control, Backstepping Sliding Mode

\section{Introduction}

With the continuous development of the auto industry and the improvement of living quality, electric power steering (EPS) system has become one of the main safety-critical components and parts of automobiles; the performance of EPS systems directly influences automobile service life and passenger safety [1].In comparison with the traditional hydraulic power steering system, the EPS system has favorably solved the "light" and "flexible" contradiction during the vehicle running process and immensely satisfied consumer requirements in the two aspects while providing a gentle road feel for the driver. Now that power steering performance is recognized, people are paying increasing attention to the return-ability of EPS systems. Timely and accurate steering returnability is the basis for favorable vehicle steering stability.Under return condition, self-return torque is generated by the vehicle's wheels to assist in steering wheel return. Different vehicle models use different tire models. Vehicle tires have a complicated structure, and the self-return torque of tires is insufficient to assist in the steering wheel's return to point zero. If the tire's return torque is smaller than the total frictional loss torque, then the

*E-mail address: sisongzhuo@126.com

ISSN: $1791-2377$ @ 2018 Eastern Macedonia and Thrace Institute of Technology. All rights reserved. doi:10.25103/iestr.113.09 steering wheel cannot return to its central position. The prerequisite of the EPS system's return control is to determine the theoretical value of return torque, which should be provided by the EPS system to avoid the insufficient return and return overshoot phenomena. The complex running conditions of vehicles, as well as the change laws of vehicle self-return torque, results in considerable challenges to return control strategy design and actual vehicle experiment[2-3]. At a theoretical level, the study of $\mathrm{Li}$ et al. indicated that multiple uncertain factors exist in the modeling of an EPS system and that the uncertain factors in the return characteristic curves degraded the system's working stability[4].

Therefore, establishing an accurate return torque model that reduces the influence of pavement disturbance on returnability must be constructed to develop the EPS system. Moreover, the observation method of the change laws of return torque in pavement disturbance environment and the compensation strategy for return torque needed by the vehicle under different working conditions remain to be the difficult points in the study of EPS return control.

\section{State of the art}

The core of EPS system is in the power-assisting motor control algorithm. Several companies write control programs into control chips of circuit boards directly and conduct 
running operations and tests to verify the rapidness, accuracy, and working stability of the response of power-assisting motor control algorithms. However, such processes consume a large quantity of manpower and material resources. Therefore, establishing a full-vehicle model using dynamic simulation software is of considerable importance in studying control algorithms. Study means of electric power system is mainly dynamics model of the system, and main motor control strategy is power steering control pattern. Zhao et al. verified the accuracy of a power-assisting motor control algorithm by adding different working parameters in the system model that direct at return overshoot at low speed and insufficient return at high speed, which are two problems of the EPS system[5]. Mo et al. proposed a fuzzy PID return control algorithm based on steering wheel angle and expounded an acquisition method for the target current curve of return control[6]. Yang et al. combined three common return torque models, namely, Mitschke model, return torque semi-empirical model, and Reimpell model, and verified that the return torque values of the three models were all affected by the slip angle and vertical load[7]. Zhu verified the effect of return torque control based on a simulation model that integrated a full-vehicle, three-degreeof-freedom model and an EPS system model [8]. Eom et al. used a nonlinear state observer to investigate the nonlinear disturbance in the system and increased the compensation control in the system to enhance robustness [9]. Lin, C.M. et al. introduced the adaptive dynamic sliding-mode fuzzy control into the control system to improve nonlinearity and uncertain factors that exist in the EPS system, which effectively reduced motor noise [10].On the basis of an established mathematical model of the EPS system, Hu et al. conducted an analytical study on the control algorithm and control logic of the EPS system, established system statespace equation, implemented simulation analysis of the system model, and analyzed the steering dynamic characteristics of the EPS system and its response to pavement disturbance [11]. The results laid a theoretical foundation for the design and practical application of EPS systems. Khan et al. used dynamic sliding-mode control for a multi-input, multi-output system to eliminate the nonlinear disturbance of system parameters [12].On the basis of an EPS model, Lee et al. analyzed system stability with approximate linear and nonlinear torque mapping and proposed the design criteria for the stability compensator [13]. In view of the problems of EPS systems in terms of high-speed vibration and steering feel, Ma et al. proposed an active anti-disturbance EPS torque control method, developed an EPS variable-pattern controller, and verified the effectiveness of an active immune algorithm via bench test [14]. Du et al. used a non-disturbance state switching logical algorithm to establish a complete active return control strategy and effectively solved the sudden change problem of the output torque of the drive motor under frequent switching between assistant steering state and RTC state [15]. By using a permanent magnet synchronous motor as the control object, Lin, F.J. et al. proposed an intelligent second-order sliding-mode control (ISOSMC) algorithm based on the wavelet fuzzy neural network of asymmetrical membership function and verified the application effectiveness of the proposed ISOSMC in EPS systems through an experiment [16]. Zhang et al. improved the return-ability of an EPS system through a steering normal fuzzy logic control scheme of the absolute position of a steering wheel angle [17].
The aforementioned studies show that the main research method of the EPS system is model simulation. Monitor control strategy refers to power steering control.However, given that actual running vehicle conditions are complicated, the steering and return conditions of the steering wheel exist when the vehicle is running. Thus, adding return control to motor control strategies is necessary. By using a full-vehicle model as the platform, an EPS system dynamics model was introduced in the present study. The observational mechanism of the response rate of vehicle return torque and the disturbance factors that influence the return-ability under pavement impact were investigated through theoretical analysis, model simulation, and performance bench test. The theoretical value of vehicle return torque was inferred starting from the self-return torque angle of the vehicle. A return control strategy was proposed based on steering wheel angle, torque, and vehicle speed and attached it to the EPS control program. On the basis of the sliding-control theory, disturbance observer was used to establish a return torque control model of the EPS system.

The remainder of this study is organized as follows. Section 3 establishes the system dynamics and return torque models of the EPS system. Section 4 analyzes vehicle return-ability using the Adams/Car joint simulation model. Section 5 summarizes the conclusions.

\section{Methodology}

\subsection{Dynamic modeling of the EPS system}

The EPS system consists of the steering wheel, steering column, torque sensor, ECU controller, power-assisting motor, and steering mechanism. The ECU controller receives the speed, engine speed, torque, and disturbance signals of the external pavement, current controls, and current direction of the power-assisting motor according to the preset control strategy. It also realizes the power steering function. Fig. 1 shows the structural chart of the EPS system.

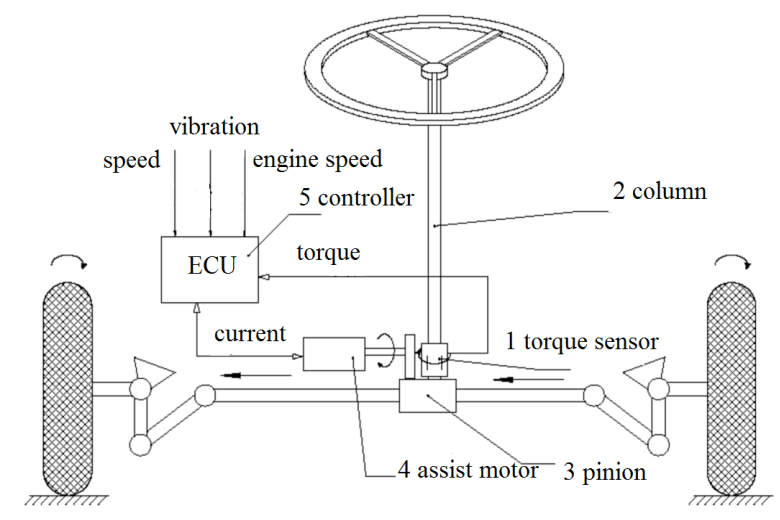

Fig. 1. Structural chart of the EPS system

The system dynamics equations of the steering column, torque sensor, output shaft, rack drive mechanism, electromotor mechanical properties, electromotor, motor power torque, and motor electromagnetic torque are established based on the structural chart of the EPS system, as shown as follows:

Steering column: 
$J_{s} \ddot{\theta}_{s}+B_{s} \dot{\theta}_{s}=T_{d}-T_{s}$

Torque sensor:

$T_{s}=k_{s}\left(\theta_{s}-\theta_{e}\right)$

Output shaft:

$J_{e} \ddot{\theta}_{e}+B_{e} \dot{\theta}_{e}=T_{s}+T_{a}-T_{w}$

Rack drive mechanism:

$m_{r} \ddot{x}_{r}+b_{r} \dot{x}_{r}+T_{w}=\frac{k_{s}}{r}\left(\theta_{s}-\frac{p}{r}\right)+\frac{k_{m} i_{m}}{r}\left(\theta_{m}-\frac{p}{r}\right)$

Mechanical properties of the electromotor:

$$
J_{m} \ddot{\theta}_{m}=T_{m}-B_{m} \dot{\theta}_{m}-k_{m}\left(\theta_{m}-\frac{p}{r} i_{m}\right)
$$

Motor mathematical model of the motor:

$U=L i_{m}+R i_{m}-K_{f} \dot{\theta}_{m}$

Motor power torque:

$$
T_{a}=k_{m} G\left(\theta_{m}-G \theta_{e}\right)
$$

Motor electromagnetic torque:

$$
T_{m}=K_{t} i_{m}
$$

where $J_{m}$ is the motor rotary inertia; $B_{s}$ is the damping coefficient of the steering column; $B_{e}$ is the damping coefficient of the reduction mechanism; $B_{m}$ is the motor damping coefficient; $\theta_{s}$ is the output shaft angle of the steering column; $\theta_{e}$ is the turning angle of the input shaft of the steering column; $T_{s}$ is the torque sensor detection value; $k_{s}$ is the torque sensor stiffness coefficient; $k_{m}$ is the motor torque coefficient; $T_{m}$ is the motor electromagnetic torque; $T_{a}$ is the motor power torque; $T_{d}$ is the steering wheel input torque; $x_{r}$ is the rack displacement; $r$ is the steering pinion radius; $i_{m}$ is the motor current; $m_{r}$ is the total mass of pinion and rack; $b_{r}$ is the rack viscosity coefficient; $L$ is the motor equivalent inductance; $R$ is the motor equivalent resistance; $K_{f}$ is the motor counter electromotive force; $G$ is the ratio of the reduction mechanism; $U$ is the motor voltage; $T_{w}$ is the acting force of tire on pavement; $J_{s}$ is the steering column rotary inertia; $J_{e}$ is the rotary inertia of the reduction mechanism; $K_{t}$ is the motor electromagnetic torque coefficient.

The system dynamics differential equations are transformed into system state control equations, and is set as the system state variable; is the system input variable; and is the system input variable. The system state equation expressed as follows:

$$
\begin{aligned}
& \dot{x}=A x+B u \\
& y=C x+D u
\end{aligned}
$$

where matrices $\mathrm{A}, \mathrm{B}, \mathrm{C}$, and $\mathrm{D}$ are the state, input, output and feedforward matrices, respectively.

$A=\left[\begin{array}{ccccccc}0 & 1 & 0 & 0 & 0 & 0 & 0 \\ -\frac{k_{s}}{J_{s}} & -\frac{k_{s}}{J_{s}} & \frac{k_{s}}{r J_{s}} & 0 & 0 & 0 & 0 \\ 0 & 0 & 0 & 0 & 0 & 0 & 0 \\ \frac{k_{s}}{r m_{r}} & 0 & -\frac{k_{s}+k_{m} G^{2}}{r^{2} m_{r}} & -\frac{b_{r}}{m_{r}} & \frac{k_{m} G}{r m_{r}} & 0 & 0 \\ 0 & 0 & 0 & 0 & 0 & 1 & 0 \\ 0 & 0 & \frac{k_{m} G}{r J_{m}} & 0 & -\frac{k_{m}}{J_{m}} & -\frac{b_{m}}{J_{m}} & 0 \\ 0 & 0 & 0 & 0 & 0 & -\frac{k_{f}}{L} & -\frac{R}{L}\end{array}\right]$

$B=\left[\begin{array}{ccc}0 & 0 & 0 \\ \frac{1}{J_{s}} & 0 & 0 \\ 0 & 0 & 0 \\ 0 & 0 & -\frac{1}{m_{r}} \\ 0 & 0 & 0 \\ 0 & 0 & 0 \\ 0 & \frac{1}{L} & 0\end{array}\right]$

$C=\left[\begin{array}{ccccccc}0 & 0 & -\frac{k_{m} G}{r} & 0 & k_{m} & 0 & 0 \\ 1 & 0 & 0 & 0 & 0 & 0 & 0 \\ 0 & 0 & 0 & 0 & 1 & 0 & 0 \\ 0 & 0 & 0 & 0 & 0 & 0 & 1 \\ k_{s} & 0 & -\frac{k_{s}}{r} & 0 & 0 & 0 & 0\end{array}\right]$

$D=[0]$

\subsection{Analysis of the return resisting torque of the steering} wheel

When the vehicle is under return condition, the control torque that must be applied by the driver to the steering wheel is the value of frictional resisting torque between tires minus the sum of tire self-return torque, return torque generated by the longitudinal force of the vehicle, return torque generated by vehicle gravity, and return torque provided by the EPS system. The frictional resisting torque between pavement and tire when the vehicle is under pivot steering condition should be calculated to determine the maximum return torque value provided by the powerassisting motor. The return torque provided by the motor, which is calculated through a theoretical formula, is the maximum return torque provided by the motor when the steering wheel conducts pivot return. A higher vehicle speed implies a greater return torque of the vehicle. The maximum hand steering power when the driver conducts pivot steering is set as . Thus, the steering torque acting on the steering wheel can be expressed as follows:

$T_{h 0}=F_{h} \times R_{s w}=10 \mathrm{~N} \cdot \mathrm{m}$ 
The computational formula for the pivot steering resisting torque is

$$
M_{s \max }=\mu_{s} \sqrt{W_{f}^{3} / p_{t}} / 3=490 N \cdot m
$$

When pivot steering resisting torque is 490 , the steering torque acting upon the steering wheel can be expressed as follows:

$$
T_{h \max }=M_{r} / i_{w 0} \times \eta=35 N \times m
$$

The assisting power that ensures pivot steering is

$$
T_{a}=T_{h \max }-T_{h 0}=25 \mathrm{~N} \cdot \mathrm{m}
$$

The maximum return assisting-power torque designed in this study is $\frac{1}{10} T_{a}=0.2 \mathrm{~N} \cdot \mathrm{m}$.

\subsection{Calculation model of the return torque of the steering wheel}

The return torque of the steering wheel is decided by the running speed of the vehicle, rotary angle of the front wheels, and factors of the automobile itself. Return torque caused by lateral force from the tire is mainly considered in the return process of the steering wheel, whereas the return torque generated by the part unrelated to the lateral force from the tire is neglected [18]. The return torque caused by the lateral force from the tire can be obtained as

$$
M_{h}=\frac{0.3144 v^{2} \delta}{343.8-0.062 v^{2}}+11.08 \sin \delta
$$

where $v$ is the running speed of the vehicle, and $\delta$ is the rotary angle of the vehicle's front wheels.

Equation (14) shows that when the vehicle speed is fixed, the rotary angle and return torque are small; and when the rotary angle is fixed, the vehicle speed is high and the return torque is small.

\subsection{Design of disturbance observer}

Irregular disturbance caused by uneven pavement and nonlinear friction between the mechanical parts of a steering system while the vehicle is running will result in poor working stability of the steering system. The basic design idea of the disturbance observer is to make the difference between the actual object and the nominal model output caused by an external disturbance and model parameter change equivalent to the control input end and then observe the equivalent disturbance of the system [19]. Fig. 3 shows the functional block diagram of the design of disturbance observer.

In Fig. 2, $\mathrm{d}$ is denotes the equivalent disturbance, $\tilde{\mathrm{d}}_{1}$ is the estimated value of the disturbance, $u$ is the controller output, and $c$ is the sliding-mode controller output. The observer output can be expressed as follows:

$$
\mathrm{u}=\mathrm{c}-\tilde{\mathrm{d}}_{1}+\mathrm{d}
$$

The low-pass filter transfer function

$$
\mathrm{Q}(s)=\frac{1}{\mathrm{~s}^{3}+2 s^{2}+s}
$$

Under zero original state, the nominal model transfer function of the control object is

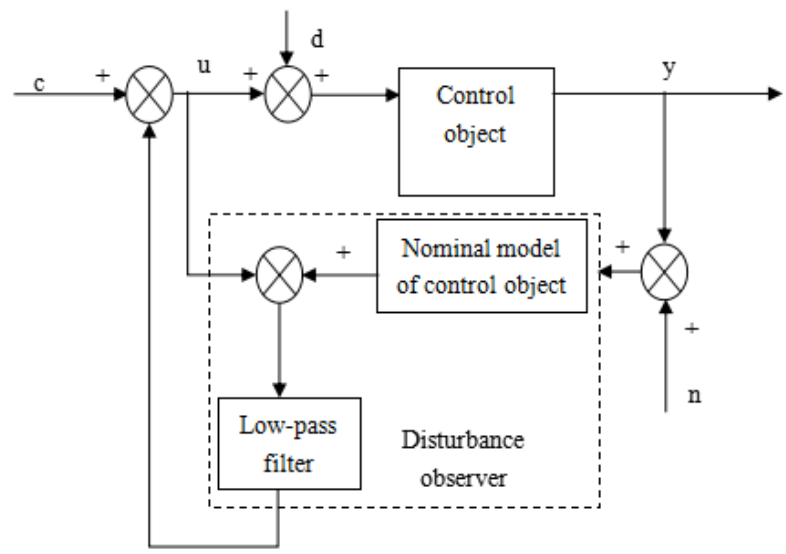

Fig. 2. Functional block diagram of disturbance observer

\subsection{Design of inverse dynamic sliding-mode controller}

The conventional sliding-mode controller contains a switchover item, which easily results in shaking. The dynamic sliding-mode control method can be used to reduce shaking effectively. The design of the sliding-mode controller can be obtained as follows.

$x=\theta_{s}$ is set. The EPS model satisfies the SISO system.

Organizing Equations (1) - (7) yields .

$\ddot{\theta}_{s}=-\frac{\mathrm{B}}{\mathrm{J}} \dot{\theta}_{\mathrm{s}}-\left(\frac{k_{m} G}{J}+\frac{G^{3} k_{m}^{2} k_{t}}{J R}\right) \theta_{s}+\frac{G^{2} k_{t} k_{m}}{J R} U+\frac{G k_{m} x_{r}}{r}$

Substituting Equation (18) into $\ddot{\mathrm{x}}=\mathrm{f}(\mathrm{x})+\mathrm{gu}+\mathrm{d}(\mathrm{t})$ yields.

$\mathrm{f}(\mathrm{x})=-\frac{B}{J} \dot{\theta}-\left(\frac{k_{m} G}{J}+\frac{G^{3} k_{t} k_{m}}{J R}\right) \theta_{s}+\frac{G^{2} k_{t} k_{m}}{J R} U+\frac{G k_{m} x_{r}}{J r}$

The rotary error of the steering wheel is defined as follows:

$\mathrm{e}_{1}=x_{1}-x_{1 d}$

where $e_{1}$ is the tracking error of the rotary angle of the steering wheel, and $x_{1 d}$ is the tracking command of $x_{1}$.

$\dot{e}_{1}$ can be derived from Equation (20), as shown as follows:

$\dot{\mathrm{e}}_{1}=\dot{x}_{1}-\dot{x}_{1 d}=\mathrm{x}_{2}-\dot{\mathrm{x}}_{1 \mathrm{~d}}$

Virtual control quantity is $\alpha_{1}$ defined as

$\alpha_{1}=-\mathrm{c}_{1} e_{1}+\dot{\mathrm{x}}_{1 d}\left(c_{1}>0\right)$

$e_{2}$ is defined as

$e_{2}=\mathrm{x}_{2}-\alpha_{1}$ 
Lyapunov function is defined as

$\mathrm{V}_{1}=\frac{1}{2} z_{1}^{2}$

Equation (24) yields.

$\dot{\mathrm{V}}_{1}=e_{1} \dot{\mathrm{e}}_{1}=\mathrm{e}_{1}\left(x_{z}-\dot{x}_{1 d}\right)=e_{1}\left(e_{2}+\alpha_{1}-\dot{x}_{1 d}\right)$

Organizing Equation (25) yields

$\dot{\mathrm{V}}_{1}=-\mathrm{c}_{1} \mathrm{e}_{1}^{2}+e_{1} e_{2}$

If $\mathrm{e}_{2}=0$, then $\dot{\mathrm{V}}_{1} \leq 0$; thus, further design is needed.

Lyapunov function is defined as

$\mathrm{V}_{2}=\mathrm{V}_{1}+\frac{1}{2} e_{2}^{2}$

Equation (23) yields

$\dot{e}_{2}=\dot{\mathrm{x}}_{2}-\dot{\alpha}_{1}=\mathrm{f}(\mathrm{x}, t) \mid b(x, t) u+c_{1} \dot{z}_{1}-\ddot{x}_{1 d}$

To satisfy $\dot{\mathrm{V}}_{2} \leq 0$, the controller is designed as follows:

$$
\mathrm{U}=\frac{1}{\mathrm{~b}(x, t)}\left[-f(x, t)-c_{2} e_{2}-e_{1}-c_{1} \dot{e}_{1}+\dot{x}_{1 d}\right]
$$

The control law of the sliding-mode controller is obtained by organizing Equation (29), as shown as follows:

$$
\begin{aligned}
& \mathrm{U}=\frac{J R}{k_{m} G R+G^{3} k_{t} k_{m}}\left[\frac{B}{J}-\theta_{s}\left(c_{2}-c_{1} c_{2}\right)-\right. \\
& \left.\dot{\theta}_{s}\left(1-c_{1}\right)+\theta_{r e f}\left(1-c_{1} c_{2}\right)+\dot{\theta}_{r e f}\left(1-c_{1}\right)\right]
\end{aligned}
$$

where $c_{1}=35, c_{2}=15$ are control parameters.

\subsection{MATLAB and Adams/Car joint simulation}

The Adams/Car dynamic simulation software is used to establish a full-vehicle model and introduce a powerassisting motor torque variable in the steering system. In the Adams/Car pinion and rack steering system, force vector is modified and assistance is added. VARIABLE 1 is a powerassisting torque variable applied by the power-assisting motor to the steering system. The pinion and rack steering system model containing the power-assisting motor torque variable is used to replace the steering system model in the Adams/Car full-vehicle model; that is, the power-assisting torque variable applied by the power-assisting motor is introduced into the full-vehicle system. Figs. 3 and 4 show the pinion and rack steering system model and the full-vehicle model, respectively.

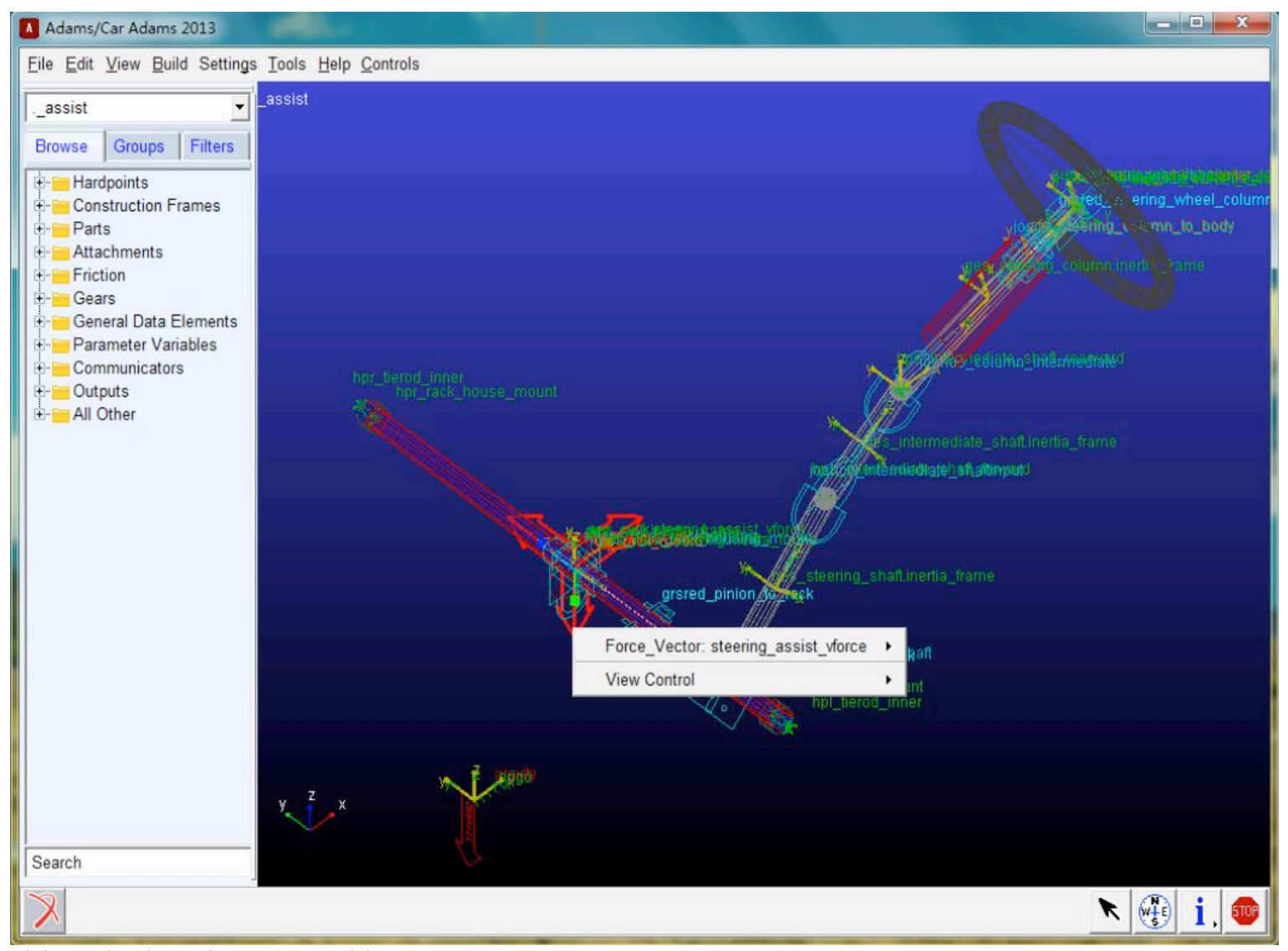

Fig. 3. Pinion and rack steering system model 


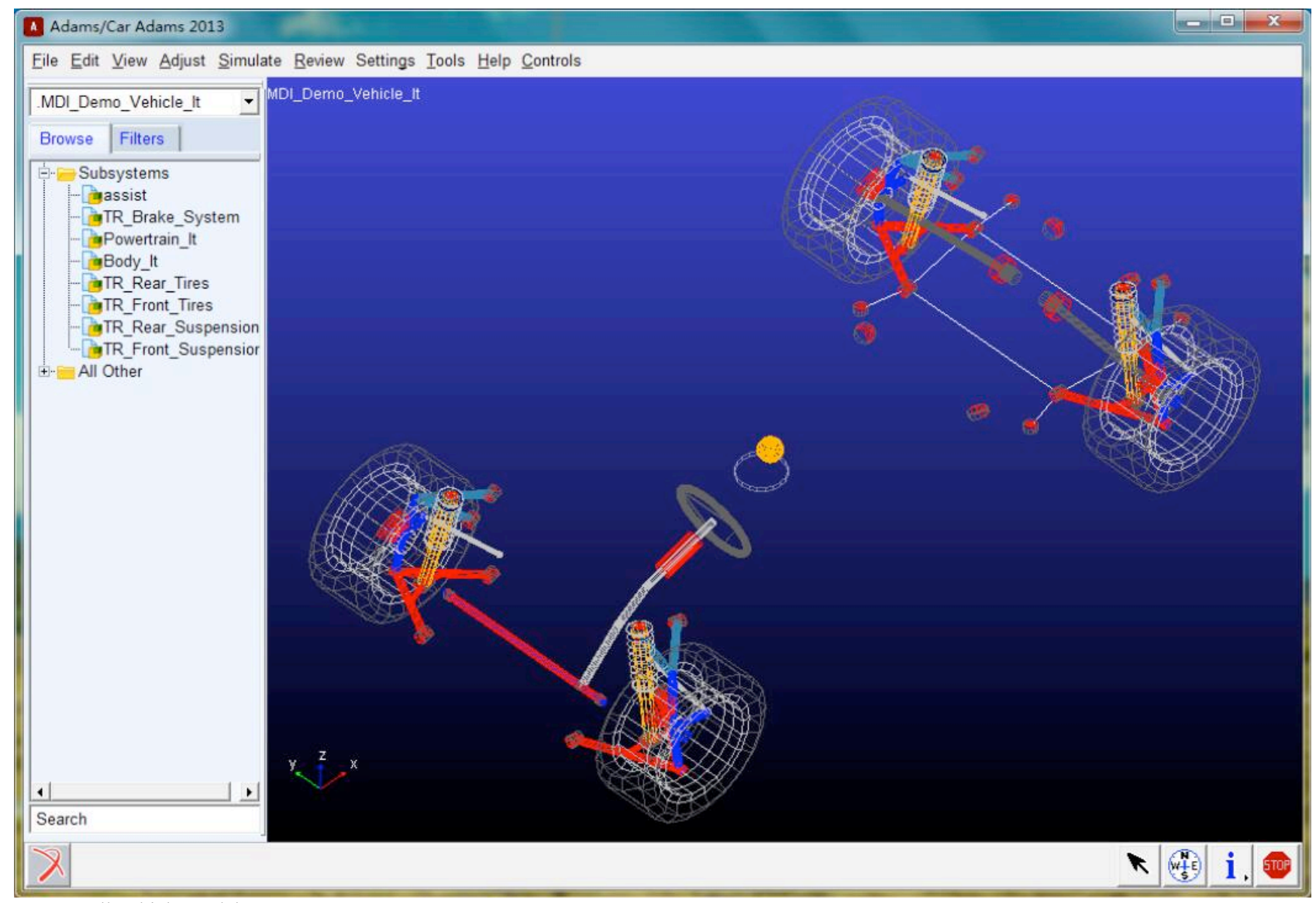

Fig. 4. Full-vehicle model

The mechanical and mathematical models of the EPS system are combined with the full-vehicle dynamics model of Adams/Car. Adams/Car outputs the full-vehicle yaw velocity, whereas the EPS system outputs the powerTable 1 lists the parameters of the EPS system. assisting motor torque that acts upon the pinion and rack steering system of the full-vehicle model. Fig. 5 shows the block diagram of the system joint simulation.

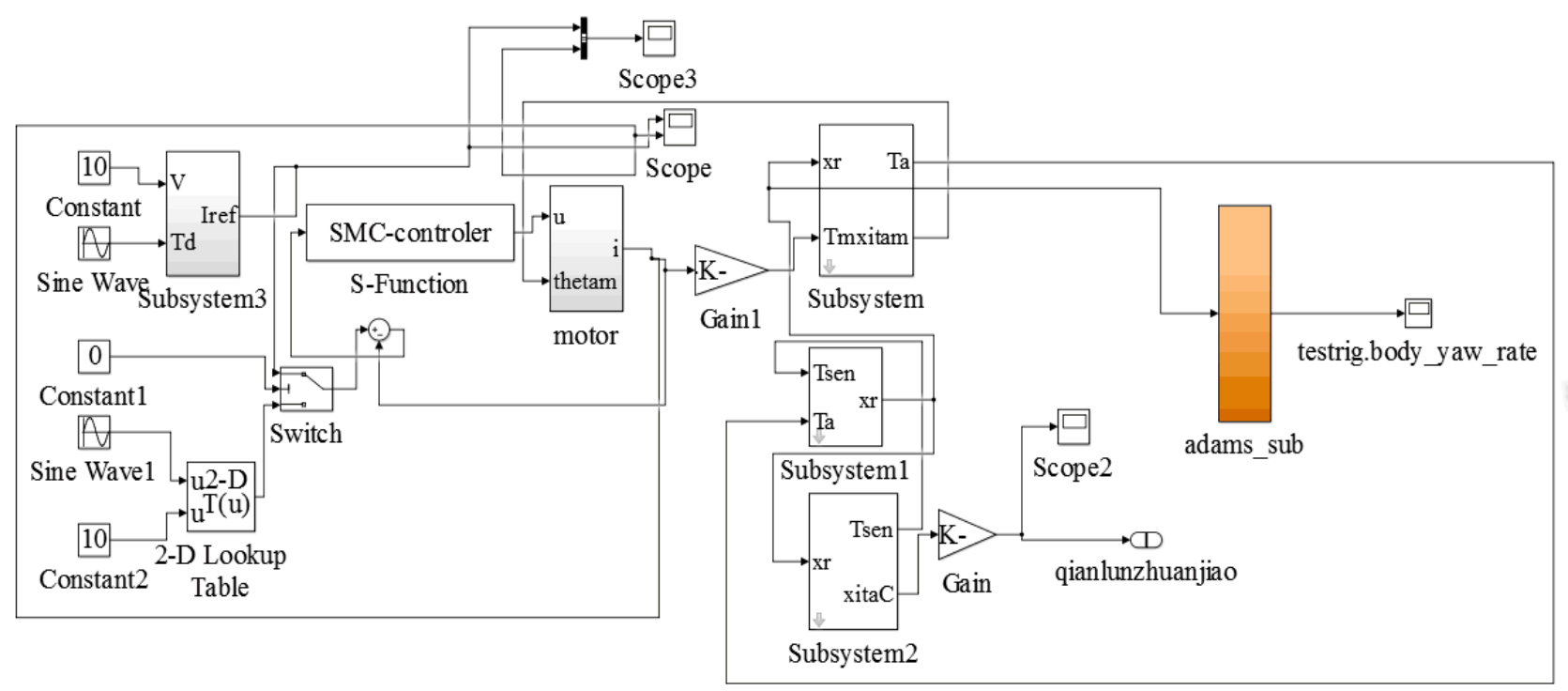

Fig. 5. Block diagram of the system joint simulation

\section{Result analysis and discussion}

The response speed of the steering wheel and the tracking accuracy of the input signal under swerving condition are the main factors that influence driving safety. Therefore, analyzing the tracking response speed of the steering wheel and vehicle yaw velocity under swerving condition is important in making an objective evaluation of the working conditions of the steering wheel and the vehicle.

\subsection{Relationship between steering wheel response speed and control algorithm}

Fig. 6 shows the step response curves of the power-assisting motor. The system response added with disturbance fast. Meanwhile, the system without disturbance observer has 
$10 \%$ overshoot after stabilization, and the system fails to

follow the input signal effectively.

Table. 1. Parameters of the EPS system

\begin{tabular}{l|l}
\hline Parameter & Value \\
\hline Motor rotary inertia $-J_{m} / \mathrm{kg} \cdot \mathrm{m}^{2}$ & 0.00002 \\
Damping coefficient of the steering column $-B_{s} / \mathrm{N} \cdot \mathrm{m} \cdot \mathrm{s} \cdot \mathrm{rad}^{-1}$ & 0.1 \\
Damping coefficient of the reduction mechanism $-B_{e} / \mathrm{N} \cdot \mathrm{m} \cdot \mathrm{s} \cdot \mathrm{rad}^{-1}$ & 0.00034 \\
Motor damping coefficient $-B_{m} / N \cdot \mathrm{m} \cdot \mathrm{s} \cdot \mathrm{rad}^{-1}$ & 0.2 \\
Total mass of pinion and rack- $m_{r} / \mathrm{kg}$ & 0.5 \\
Rack viscosity coefficient $-b_{r}$ & 3820 \\
Motor equivalent inductance $-L / H$ & 0.0001 \\
Motor equivalent resistance $-R / \Omega$ & 0.2 \\
Motor torque coefficient $-k_{m}$ & 55 \\
Stiffness coefficient of the torque sensor $-k_{s}$ & 103 \\
Ratio of the reduction mechanism $-G$ & 30 \\
Rotary inertia of the steering column- $-J_{s} / \mathrm{kg} \cdot \mathrm{m}^{2}$ & 11.5 \\
Rotary inertia of the reduction mechanism $-J_{e} / \mathrm{kg} \cdot \mathrm{m}^{2}$ & 18 \\
Motor electromagnetic torque coefficient $-K_{t}$ & 0.046 \\
\hline
\end{tabular}

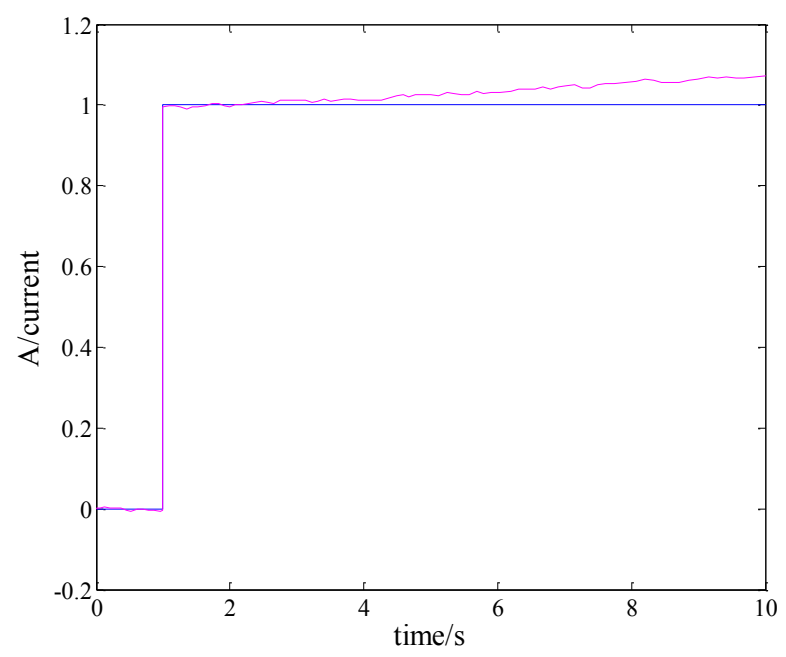

Fig. 6. Current step response

Fig. 7 shows the sinusoidal response curves of the power-assisting motor. From the figure, the system response added with disturbance observer does not have an overshoot, and the motor response speed is fast. Meanwhile, the system without disturbance observer has $10 \%$ overshoot after stabilization, and the system fails to follow the input signal effectively.

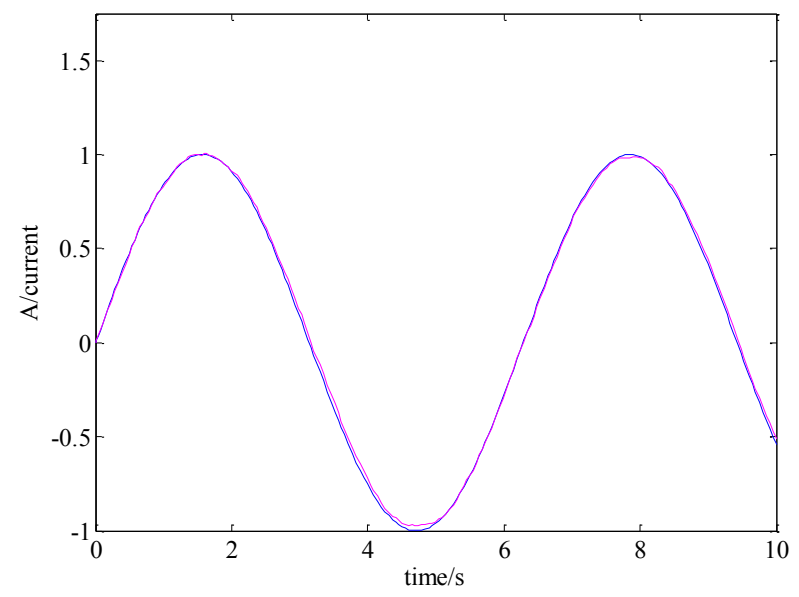

Fig. 7. Current sinusoidal response
4.2 Relationship between the return residual angle of the steering wheel and the control algorithm

Fig. 8 shows that the residual angle of the steering wheel added with active return control is at $5^{\circ}$, whereas the one without active return control is $20^{\circ}$. The experimental results show that the residual angle of the steering wheel reduces by $15^{\circ}$ when the vehicle added with active return control is returning at a low speed.

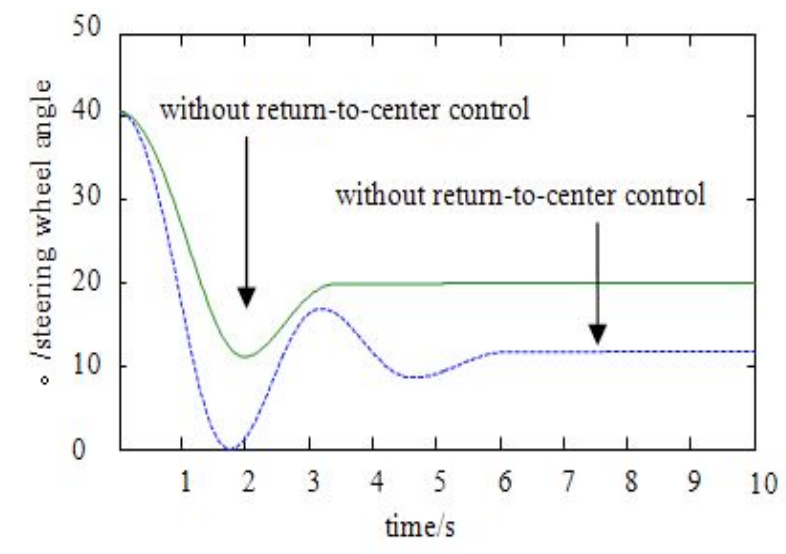

Fig. 8. Return residual angle of the steering wheel

\section{3. Relationship between vehicle running stability and control algorithm}

The vehicle speed is at $60 \mathrm{~km} / \mathrm{h}$, and the steering wheel is loosened after rotating at $40^{\circ}$ (Fig. 9). With sliding-mode return control, the steering wheel is stable at $5.8 \mathrm{~s}$ with a return residual angle of $9^{\circ}$. By contrast, without the return control, vibrations are observed and the steering wheel is stable at $3.2 \mathrm{~s}$ with a return residual angle at $20^{\circ}$.

The curves in Fig. 10 show the input torque-motor current characteristic curves of the power-assisting motors with vehicle velocities of $40 \mathrm{~km} / \mathrm{h}$ and $60 \mathrm{~km} / \mathrm{h}$, respectively. The input torque of the steering wheel is within $2.5 \mathrm{~N} \cdot \mathrm{m}$ in the dead zone of the controller; that is, the return powerassisting torque provided by the power-assisting motor after the driver loosens the steering wheel is $2 \mathrm{~N} \cdot \mathrm{m}$. 


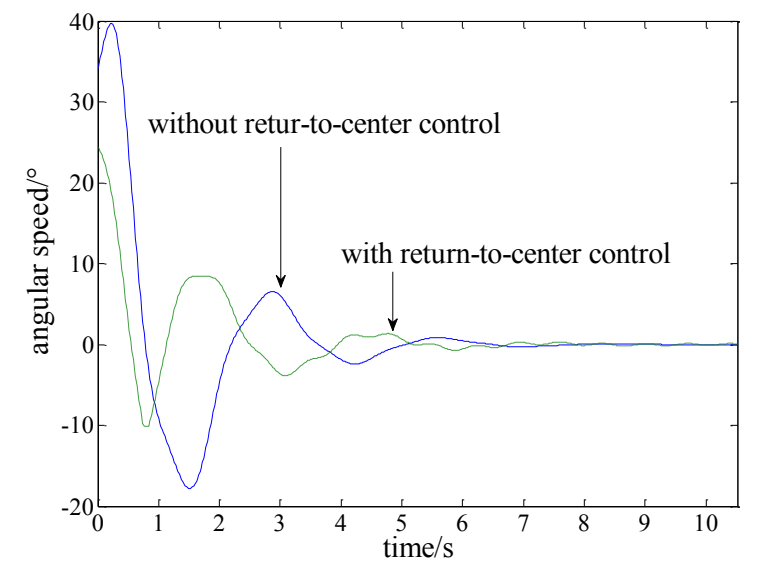

Fig. 9. Vehicle yaw velocity

\section{Conclusions}

To eliminate adverse the effect of pavement disturbance and uncertain factors of the model on the working stability of the EPS system, the theoretical value of the vehicle return torque was analyzed and a return control strategy was established based on the EPS system and full-vehicle model. The reliability of the algorithm was verified through model simulation and performance bench test. From the study, the following conclusions can be drawn:

(1) Vehicle self-return torque model is a theoretical basis for establishing the return power-assisting torque of the EPS system, and disturbance observer can effectively reduce the effects of uncertain factors of the pavement and system model on the stability of the return torque of the steering wheel.

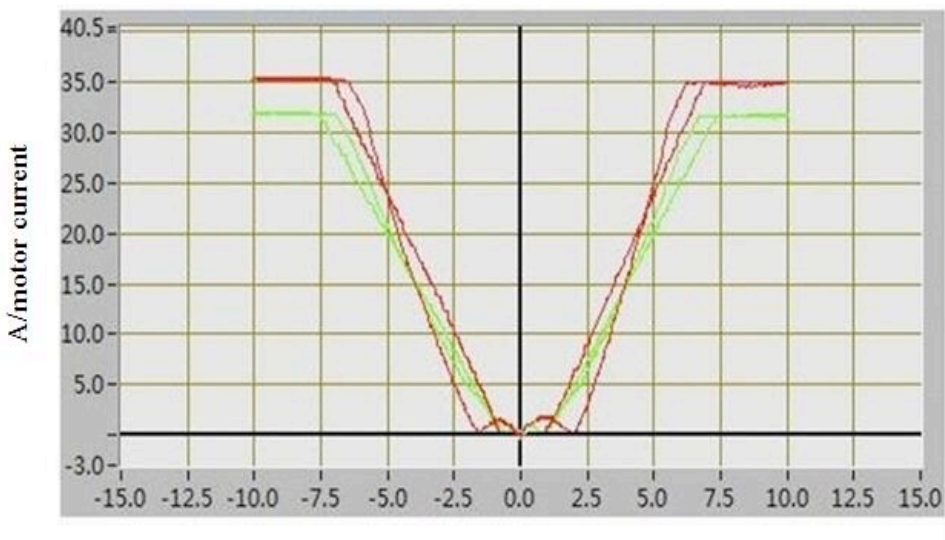

time/s

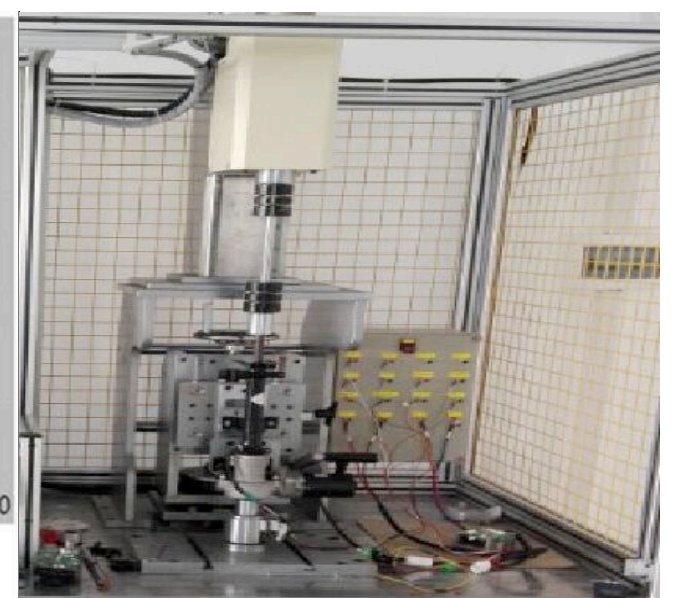

Fig. 10. Performance bench input torque - motor current characteristic curves of the controller

(2) The vehicle yaw velocity-power-assisting motor response characteristic curves show that adding return control can improve vehicle running stability. When the vehicle is returning at a low speed, return control can make the residual angle of the steering wheel return to smaller than $5^{\circ}$; this value of the residual angle meets the indicator requirement of the steering system industry for return residual angles.

In summary, disturbance state observer was introduced into the EPS control system, and the return control strategy for the steering wheel was proposed. The established model could reflect the actual state of a running vehicle. This method could be applied to return simulations and theoretical modeling studies of different automobile models. Given that the EPS system control model has several nonlinear factors, uncertainty and nonlinear time lag system models should be established to improve control accuracy.

\section{Acknowledgements}

The work was supported by supported by the Fundamental Research Funds for the Central Universities (2572015AB19).

This is an Open Access article distributed under the terms of the Creative Commons Attribution License

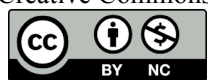

\section{References}

1. Lin, Y., Shi, G. B., Zou, C. F., W, W. Y., "Study on Object Evaluation of Steering Performance of Electric Power Steering". Transactions of The Chinese Society of Agricultural Machinery, 4(34), 2003, pp.4-7.

2. Bei, S. Y., Zhao, J. B., Liu, H. M., Sun, L. J., Chen, L., "Automotive EPS Motor Control Strategy Including Special Steerin g Situations". Journal of System Simulation, 18(21), 2009, pp.58865891 and 5895.

3. Li, Z. P., and Shi, S. Z., "Stability of EPS system of agricultural vehicles under vibration environment". INMATEHAGRICULTURAL ENVIRONMENT, 1(51), 2017, pp.101-110.
4. Li, S. S., Z, C. F., W, Z. X., L, M. H., W, W. R., W, H., "Active return-to-center control method for electric power steering". Journal of Jilin University(Engineering and Technology Edition), 46(2), 2012, pp.1355-1359.

5. Z, L. F., C, W. W., L, G., "Modeling and Verifying of EPS at ALL operating Conditions". Transactions of the Chinese Society for Agricultural Machinery, 10(40), 2009, pp.1-7.

6. M, X. H., L, Z. X., Y, H., L, B. D., "A Return-to-central Control Strategy for Electric Power Steering System by Controlling the Velocity of steering Wheel". Mechanical Science and Technology for Aerospace Engineering, 6(36), 2017, pp.848-854.

7. Y, X. Y., L, S. M., L, N., X, T. F., "Comparison and Simulation of Aligning Torque Models of Vehicle SteeringSystem". Machinery Design \& Manufacture, 2(2), 2016, pp.258-262. 
8. Zhu, H. W., "Research and realization of initiative return-to-center control for electric power steering system". Master thesis of Xi-hua University, China, 2014, pp.22-23.

9. Eom, M., and Chaw, D., "Robust Swing-Up and Balancing Con-trol Using a Nonlinear Disturbance Observer for the Pen-dubot System With Dynamic Friction”. IEEE Transactions on Robotics, 31(2), 2015, pp.331-343.

10. Lin, C. M., and L, H. Y., "Adaptive dynamic sliding-mode fuzzy CMAC for voice coil motor using asymmetric gaussian membership function". IEEE Transactions on Industrial Electronics, 61(10), 2014, pp.5662-5671.

11. H, J. J., L, J. Q., D, D. T., L, H., "Modeling and Simulation of Electric Power Steering System". JOURNAL OF CHONGQING UNIVERSITY(NATURAL SCIENCE EDITION), 30(8), 2007, pp.1013.

12. Khan, Q., Bhatyia, I., Ferrara, A., "Dynamic sliding mode control design based on an integral manifold for non-linear uncertain systems".Journal of Nonlinear Dynamics, 2(1), 2014, pp.1-10.

13. Lee, D., Kim, K.S., Kim, S., "Controller Design of an Electric Power Steering System". IEEE Transactions on Control Systems Technology , 26(2), 2018, pp.1-8.
14. Ma, X., Guo, Y., Chen, L., "Active disturbance rejection control for electric power steering system with assist motor variable mode". Journal of the Franklin Institute, 335(3), 2018, pp.1139-1155.

15. Du, P. P., Su, H., Tang, G. Y., "Active Return-to-Center Control Based on Torque and Angle Sensors for Electric Power Steering Systems". Sensors, 18(3), 2018, pp.1-12.

16. Lin, F. J., Hung, Y. C., Ruan, K. C., "An Intelligent Second-Order Sliding-Mode Control for an Electric Power Steering System Using a Wavelet Fuzzy Neural Network". IEEE Transactions on Fuzzy Systems, 22 (6), 2014, pp.1598-1611.

17. Zhang, Y., and Chen, N., "Method of Electric Power Steering Based on Return-To-Center Control".In: Asia-pacific Power \& Energy Engineering Conference, Chengdu, China:IEEE 2010,pp.1-3.

18. Li, Z., "Design of steering wheel force feedback system for vehicle driving simulator". Master thesis of Southwest Jiaotong University, China, 2009, pp.22-23.

19. Chen, W. H., "A nonlinear disturbance observer for robotic manipulators". IEEE Transactions on industrial Electronics, 47(4), 2000,pp.932-938 